Supporting Information

Anthracene-Functionalized Polystyrene Random Copolymers: Effects of Side-Chain Modification on Polymer Structure and Behavior

Roy Shenhar, Amitav Sanyal, Oktay Uzun, and Vincent M. Rotello

Department of Chemistry, University of Massachusetts, Amherst, MA 01003

PS/CMS (19,20\%) - GPC

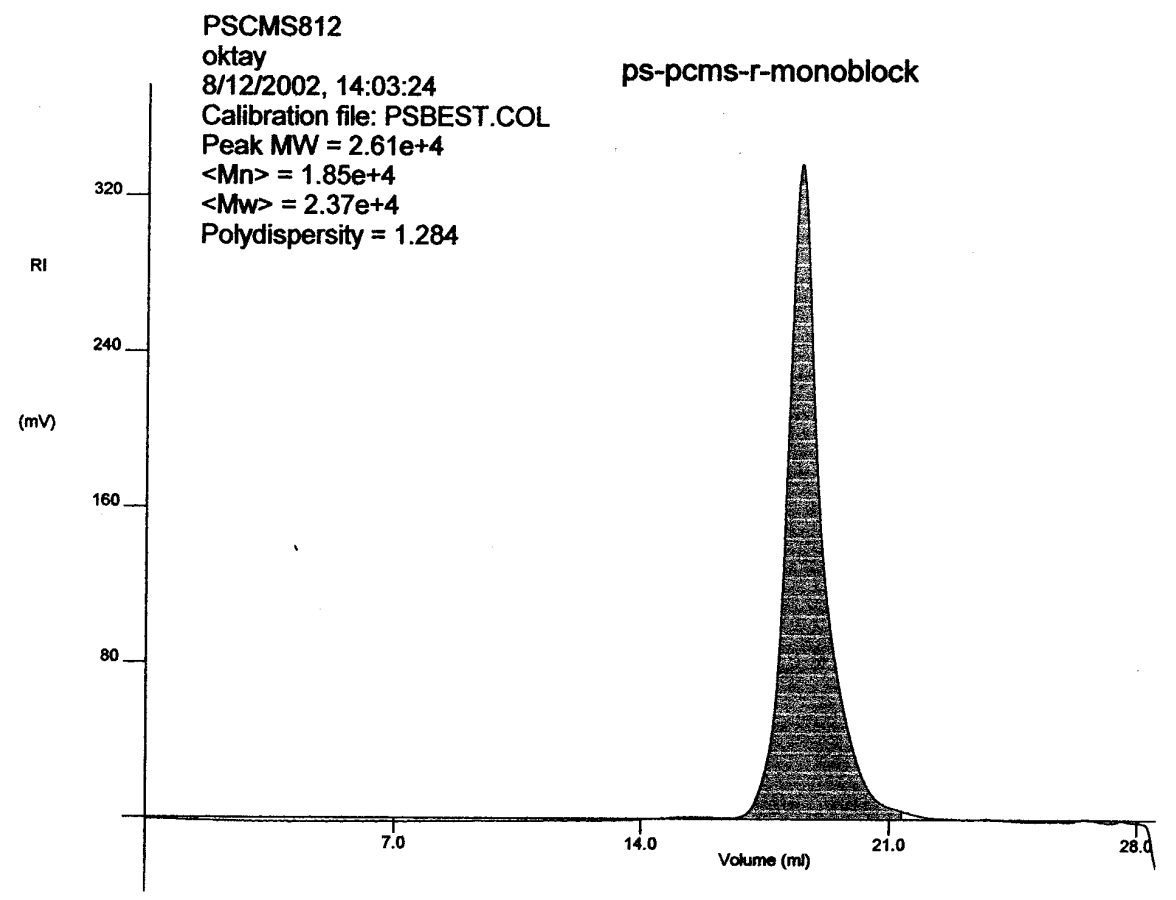




\section{PS/CMS (19,20\%) - NMR}

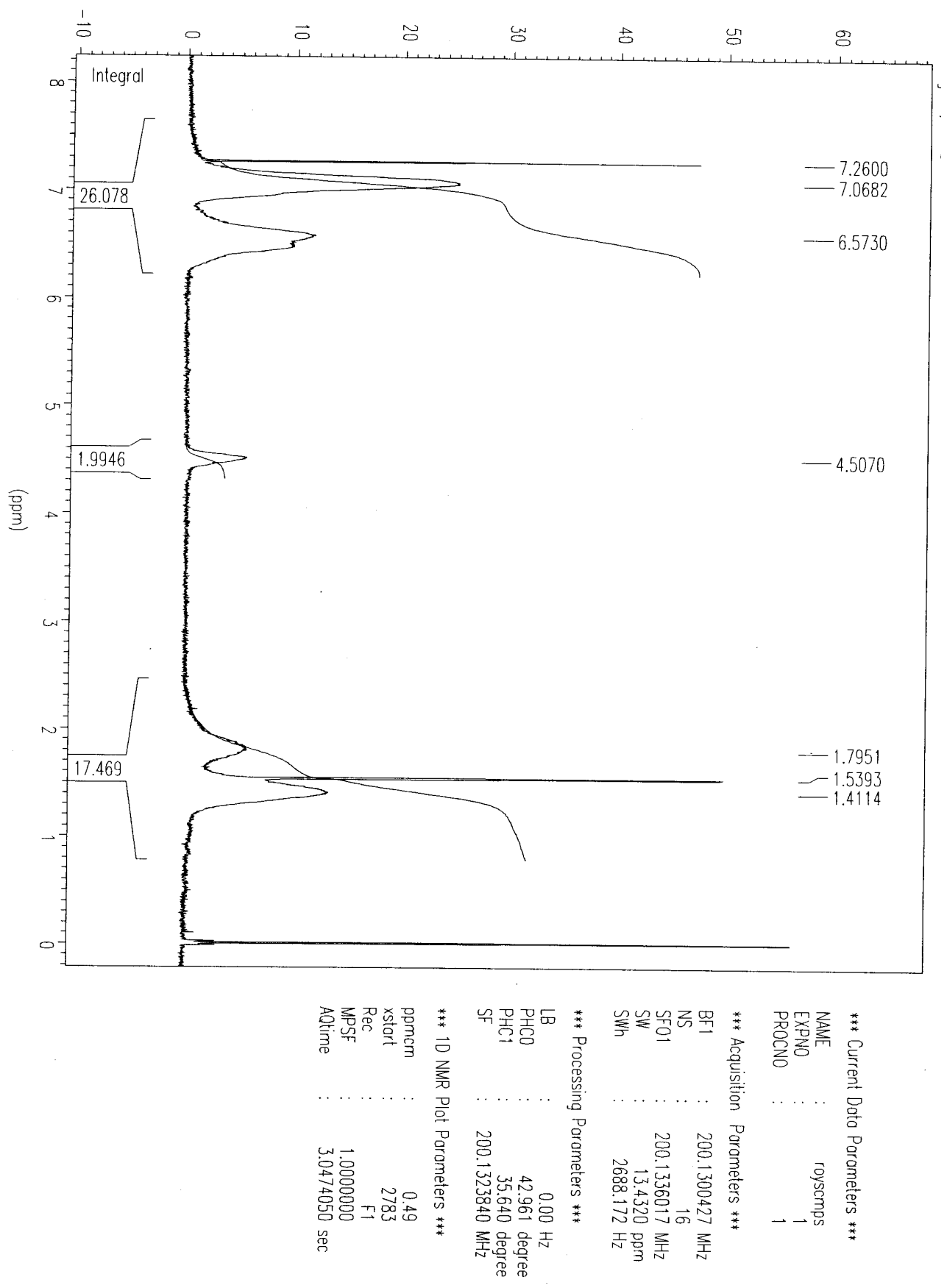




\section{PS/S-Anth/CMS (19,7\%,13\%) - NMR}

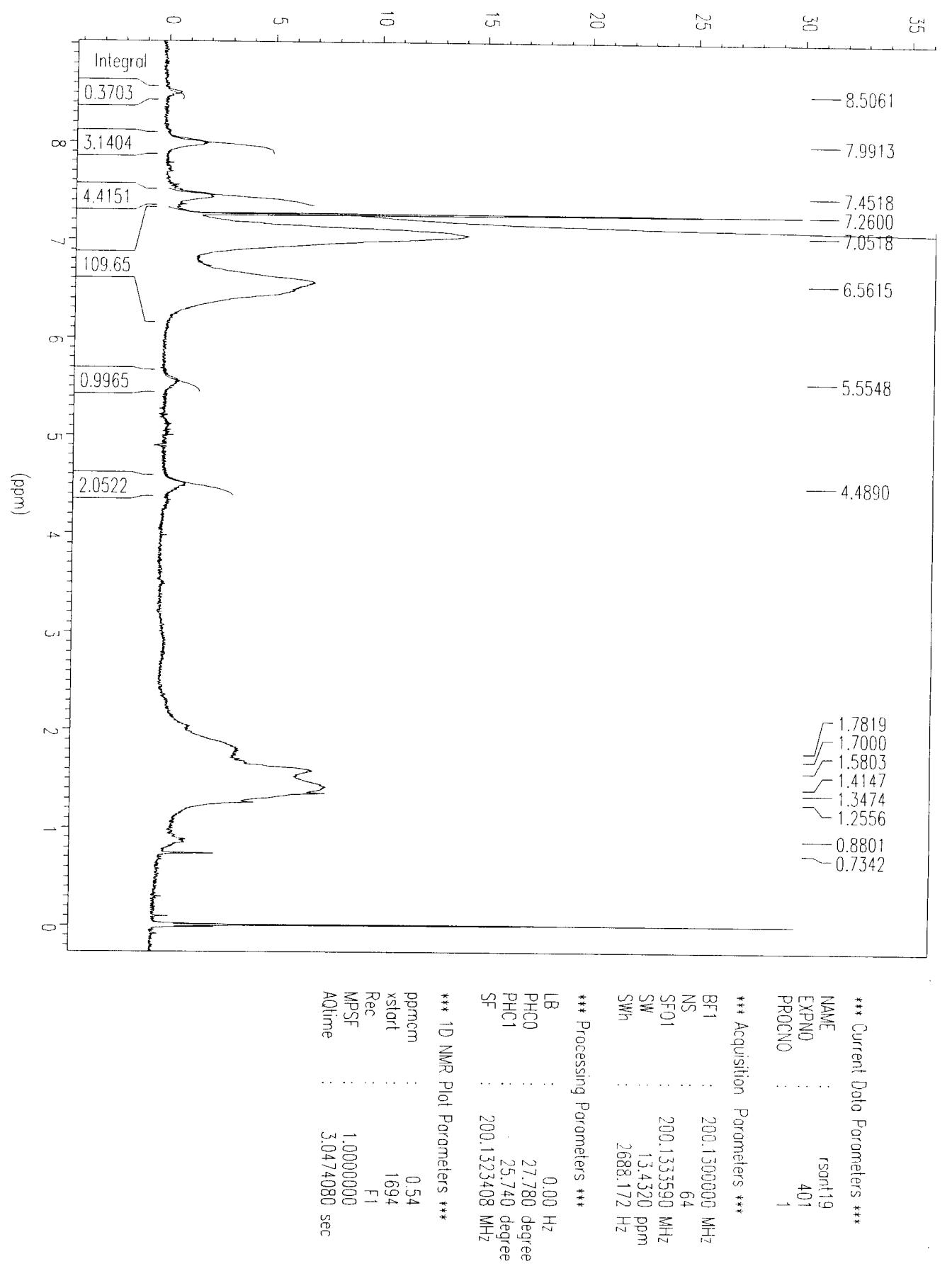




\section{PS/S-Anth/CMS $(19,12 \%, 8 \%)$ - NMR}

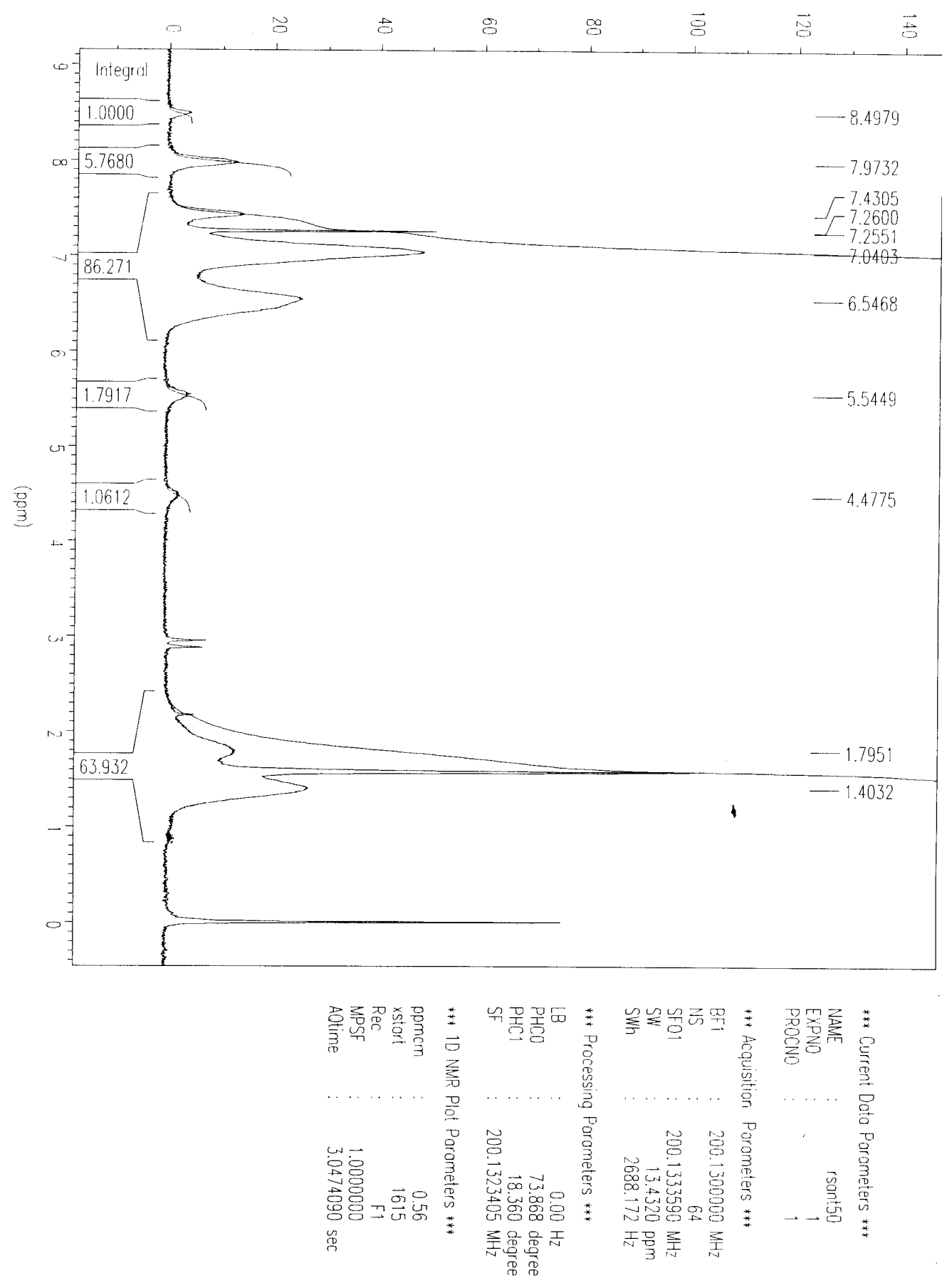


PS/S-Anth (19,20\%) - NMR

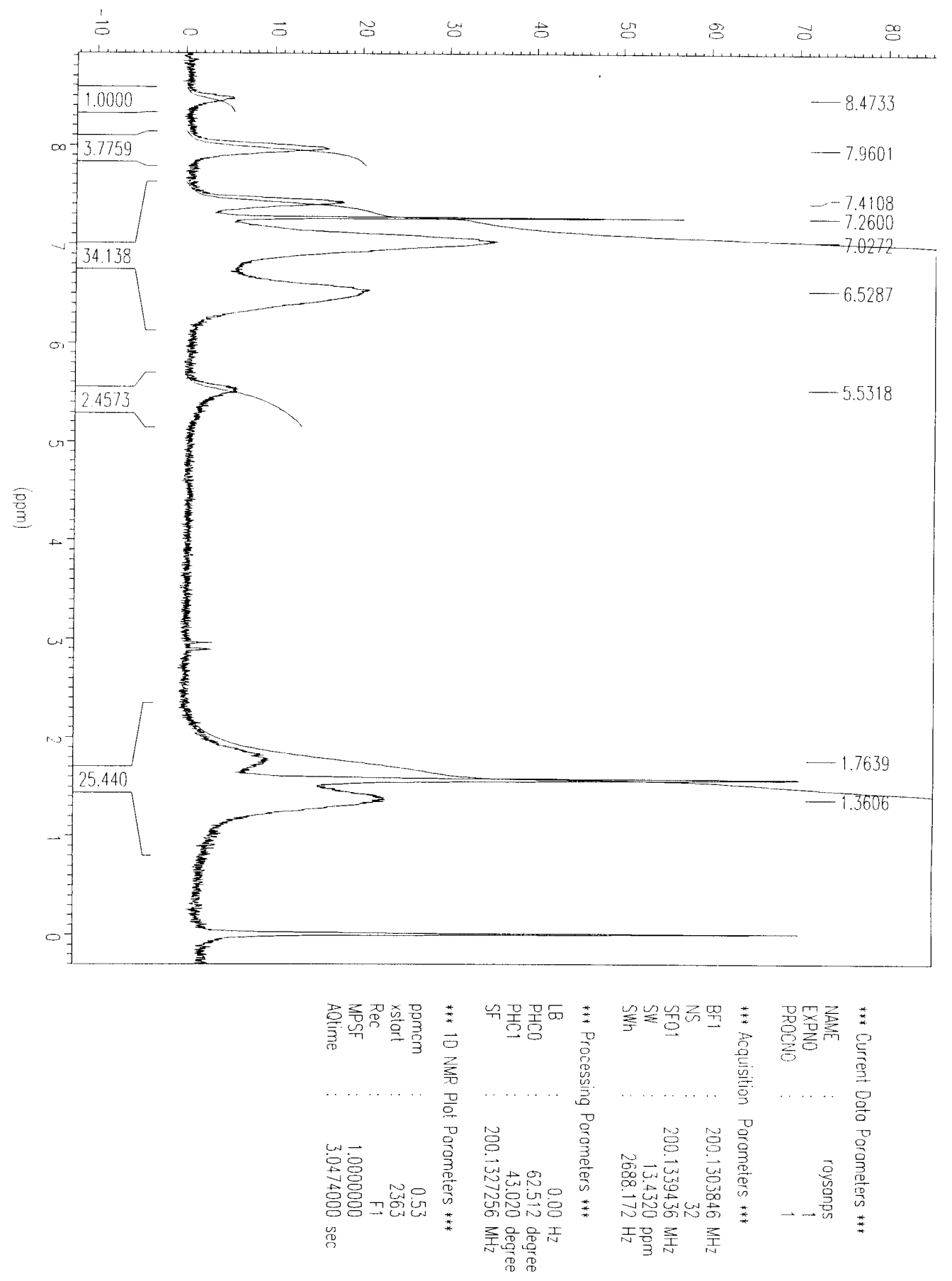




$$
-1
$$




\section{PS/CMS (25,50\%) - NMR}
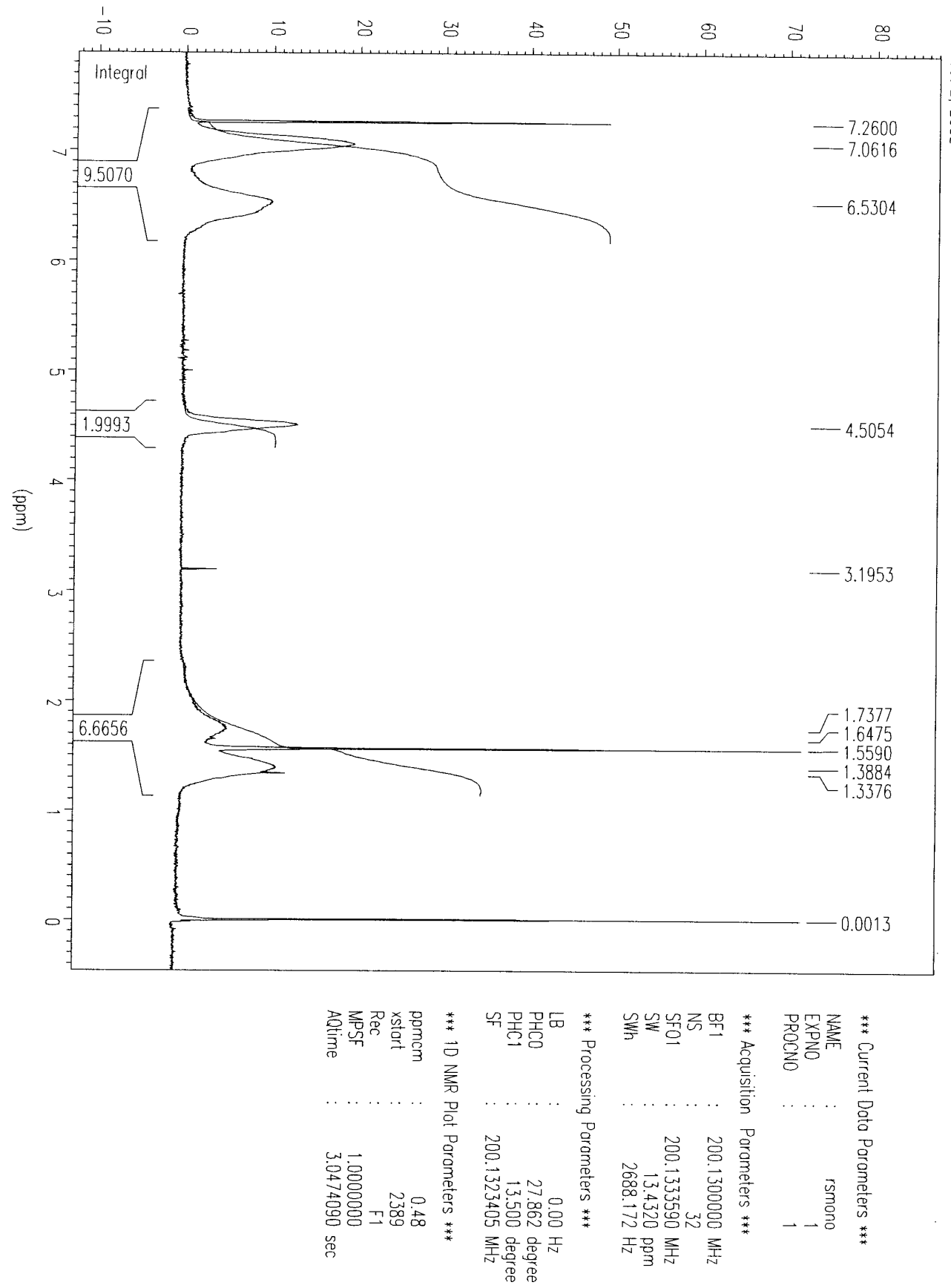
PS/S-Anth (25,50\%) - NMR

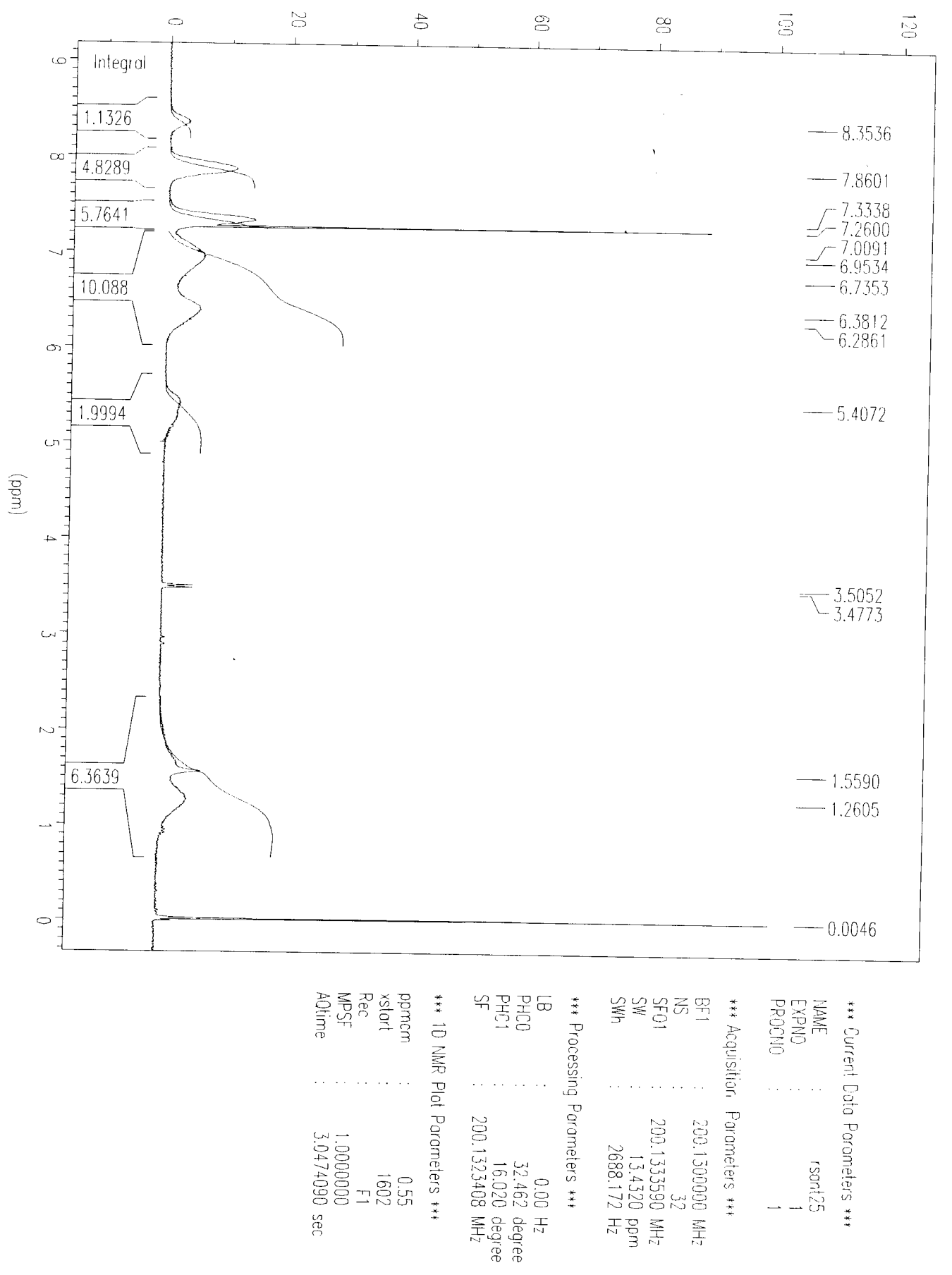


PS/CMS (27:13,17\%) - GPC

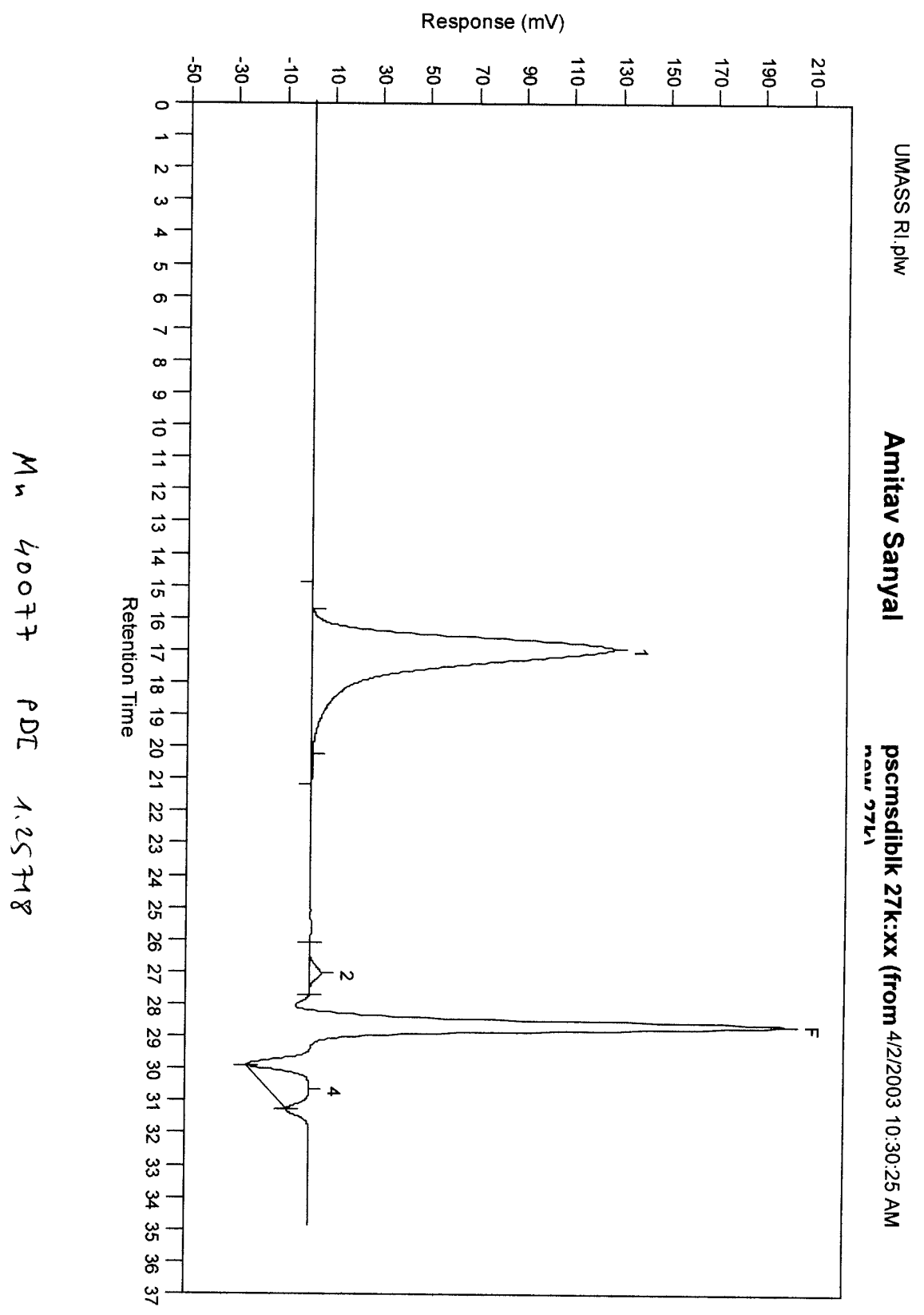




\section{PS/CMS (27:13,17\%) - NMR}

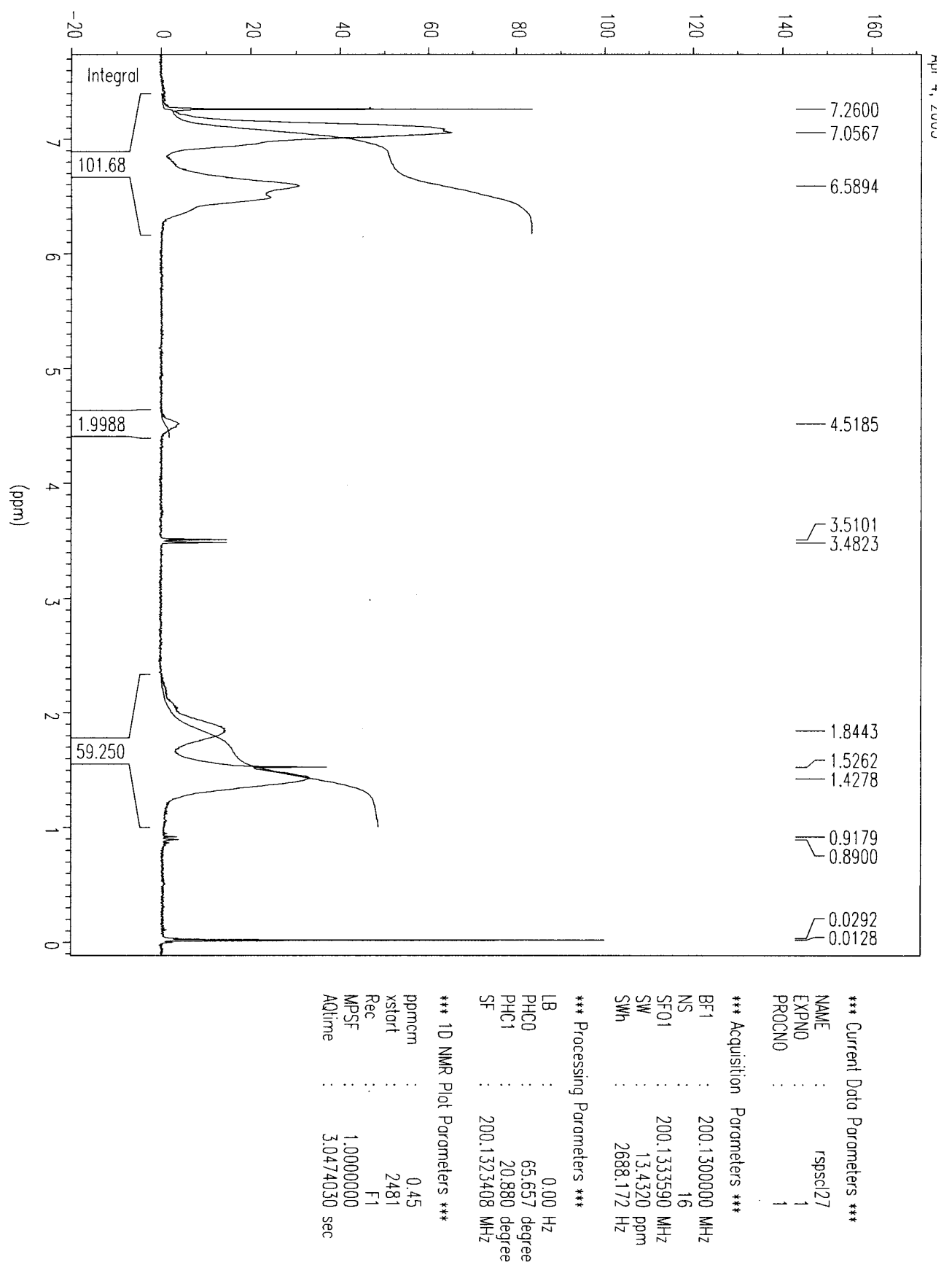




\section{PS/S-Anth (27:13,17\%) - NMR}

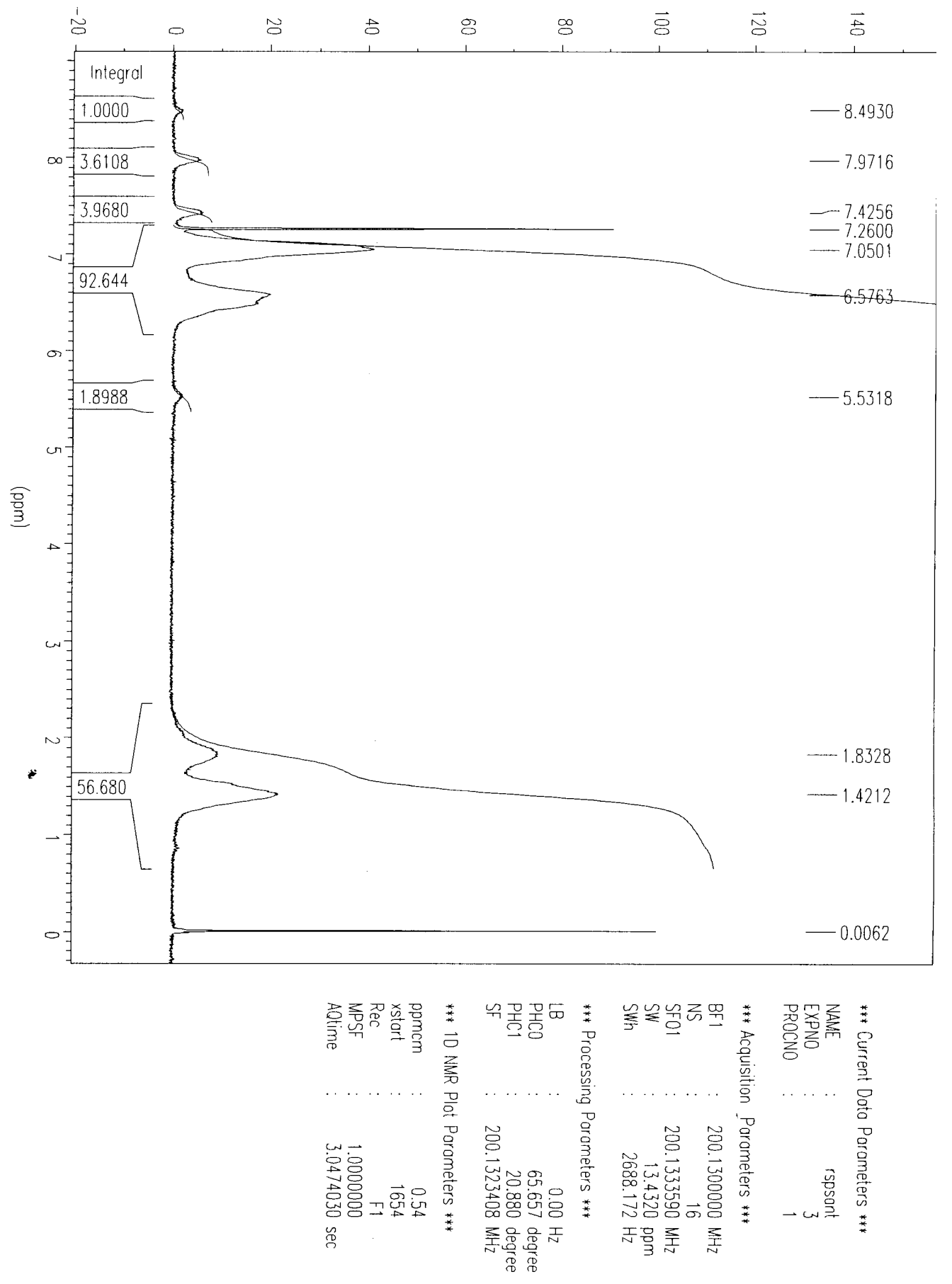


S12

PS/CMS (27:13,25\%) - GPC

Response (mV)

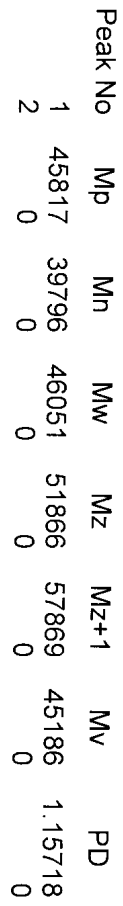

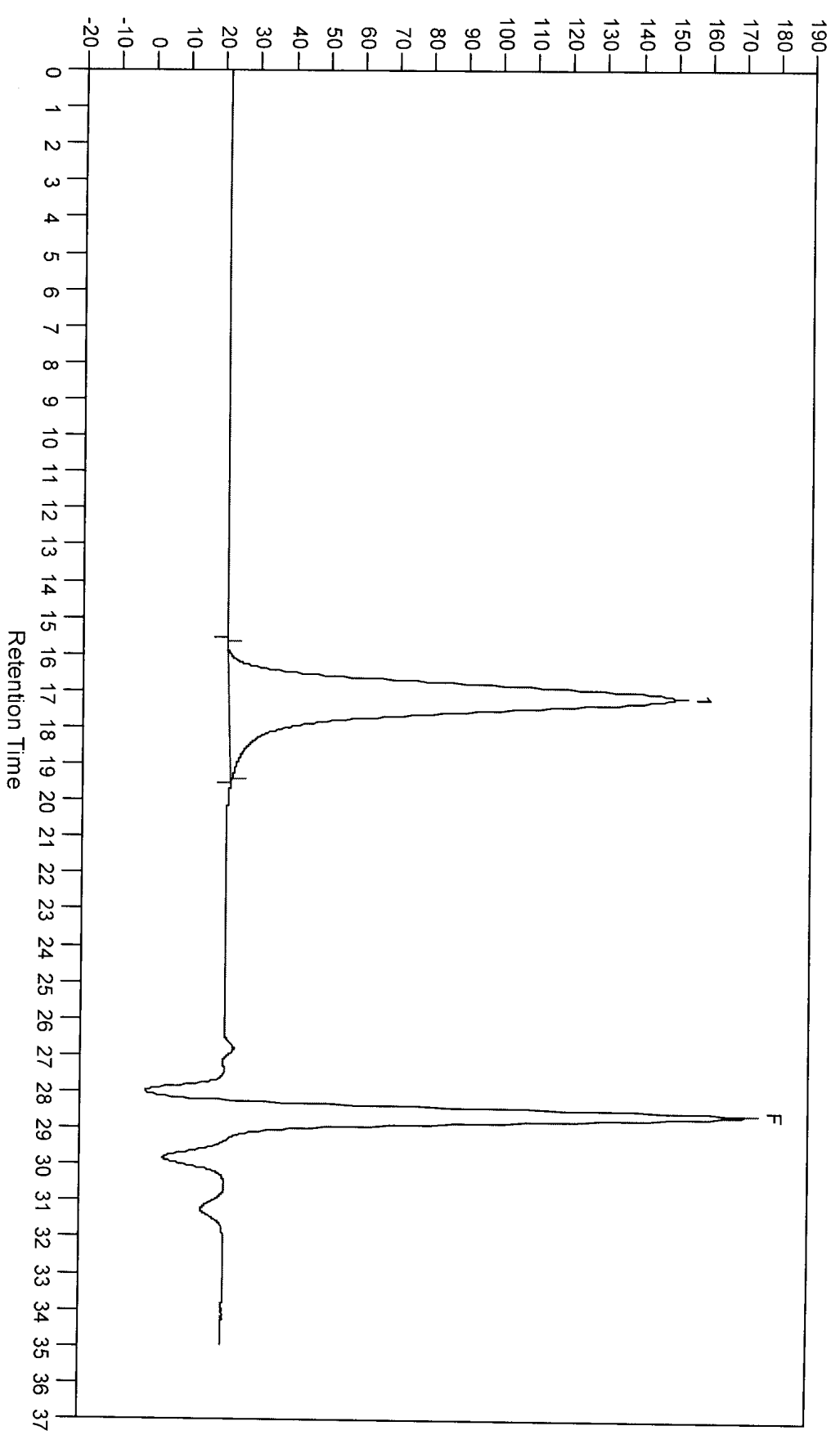

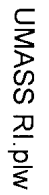

ֻ

D
$\dot{1}$
$\dot{1}$
o
$\dot{D}$

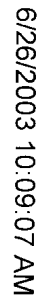


S13

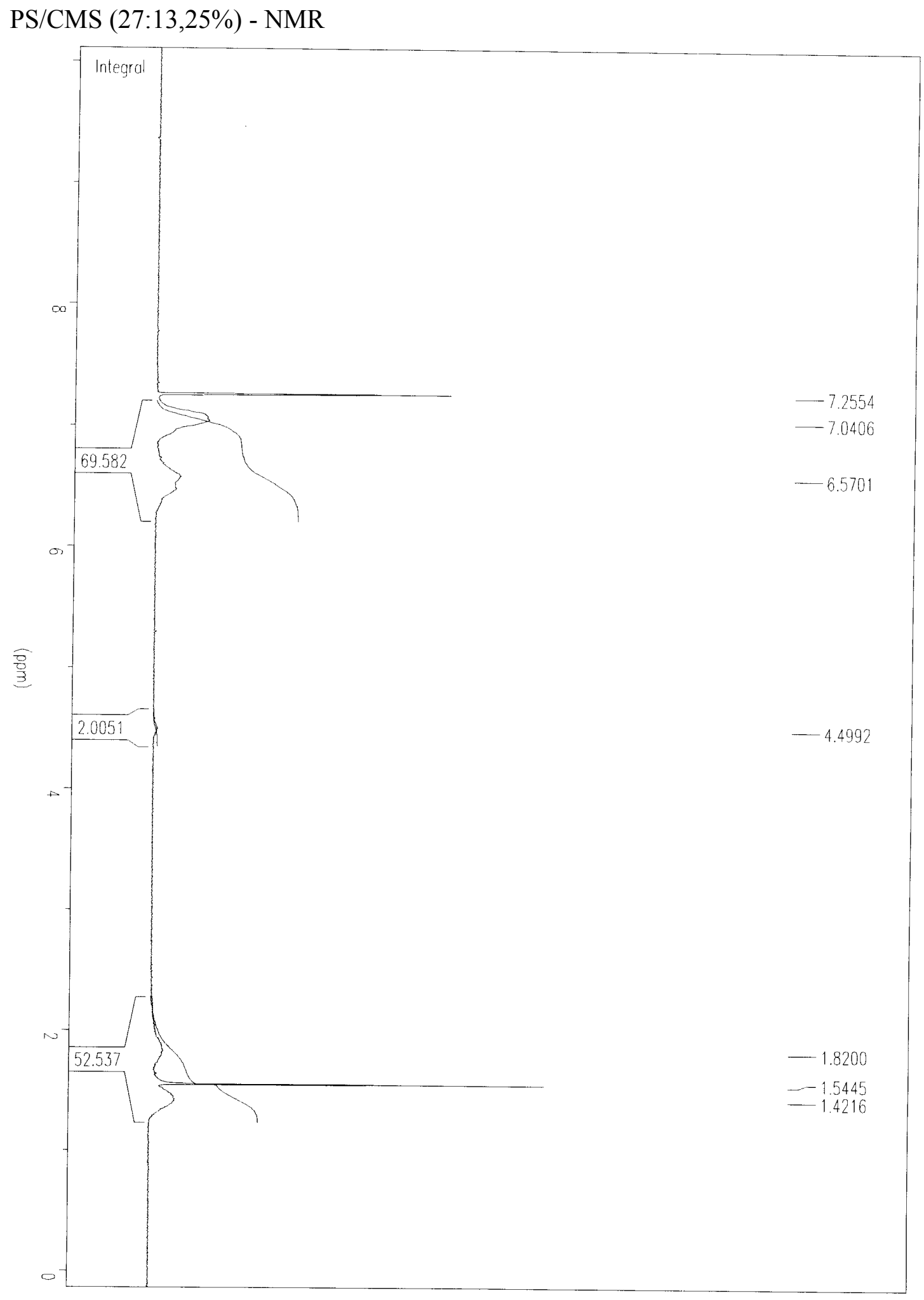


PS/S-Anth (27:13,25\%) - NMR

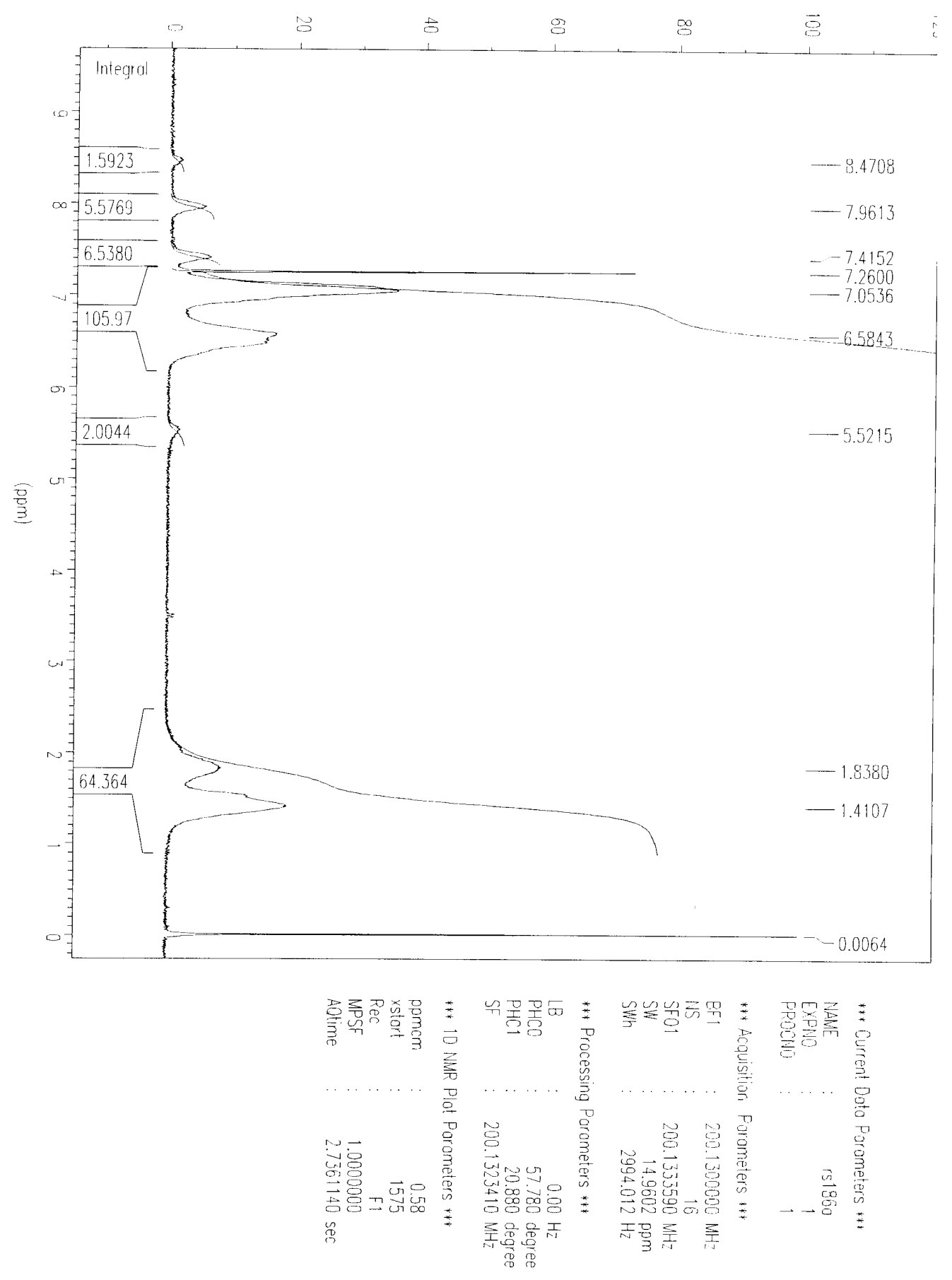


PS/CMS (28:13,40\%) - GPC

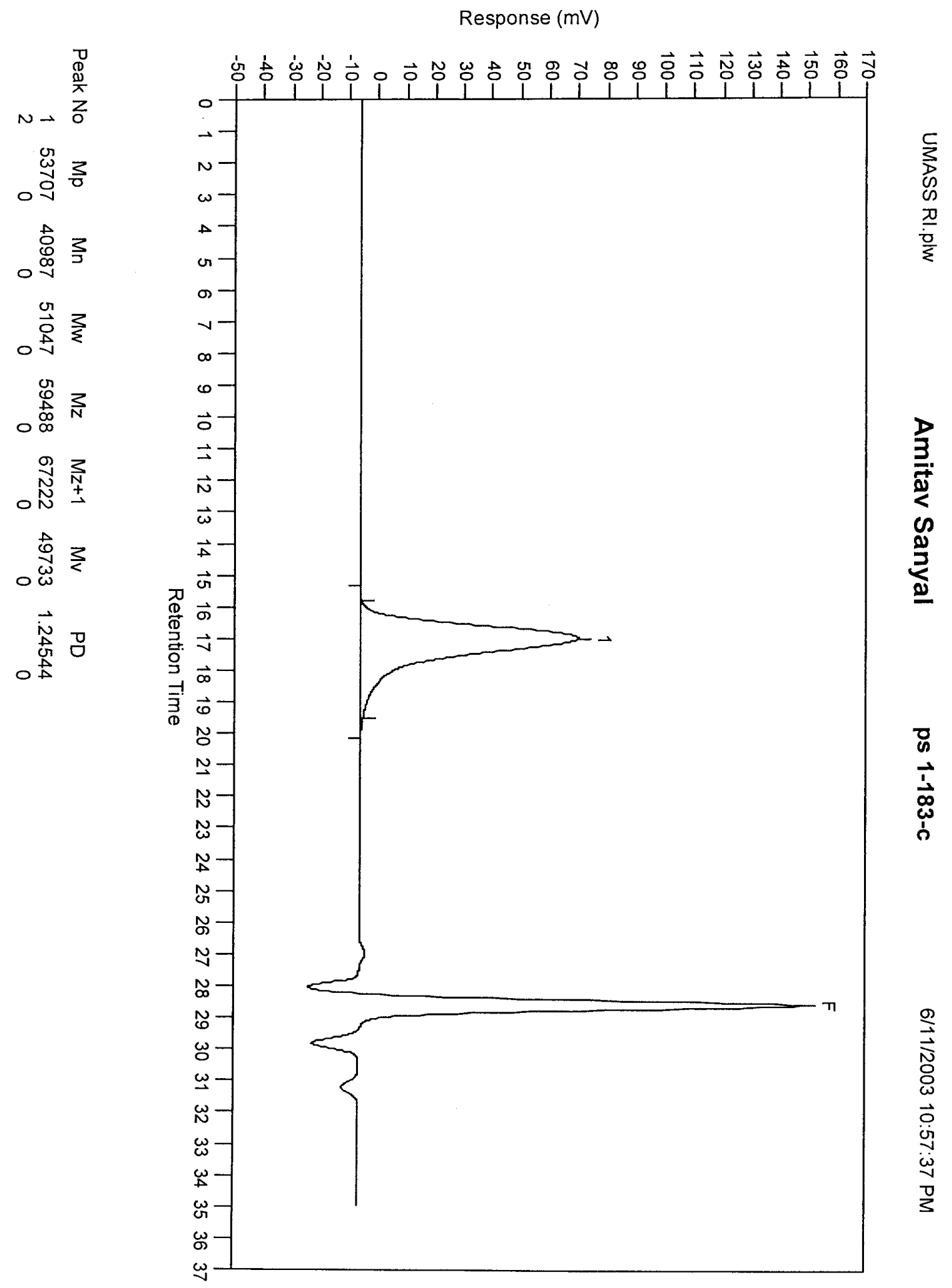




\section{PS/CMS (28:13,40\%) - NMR}

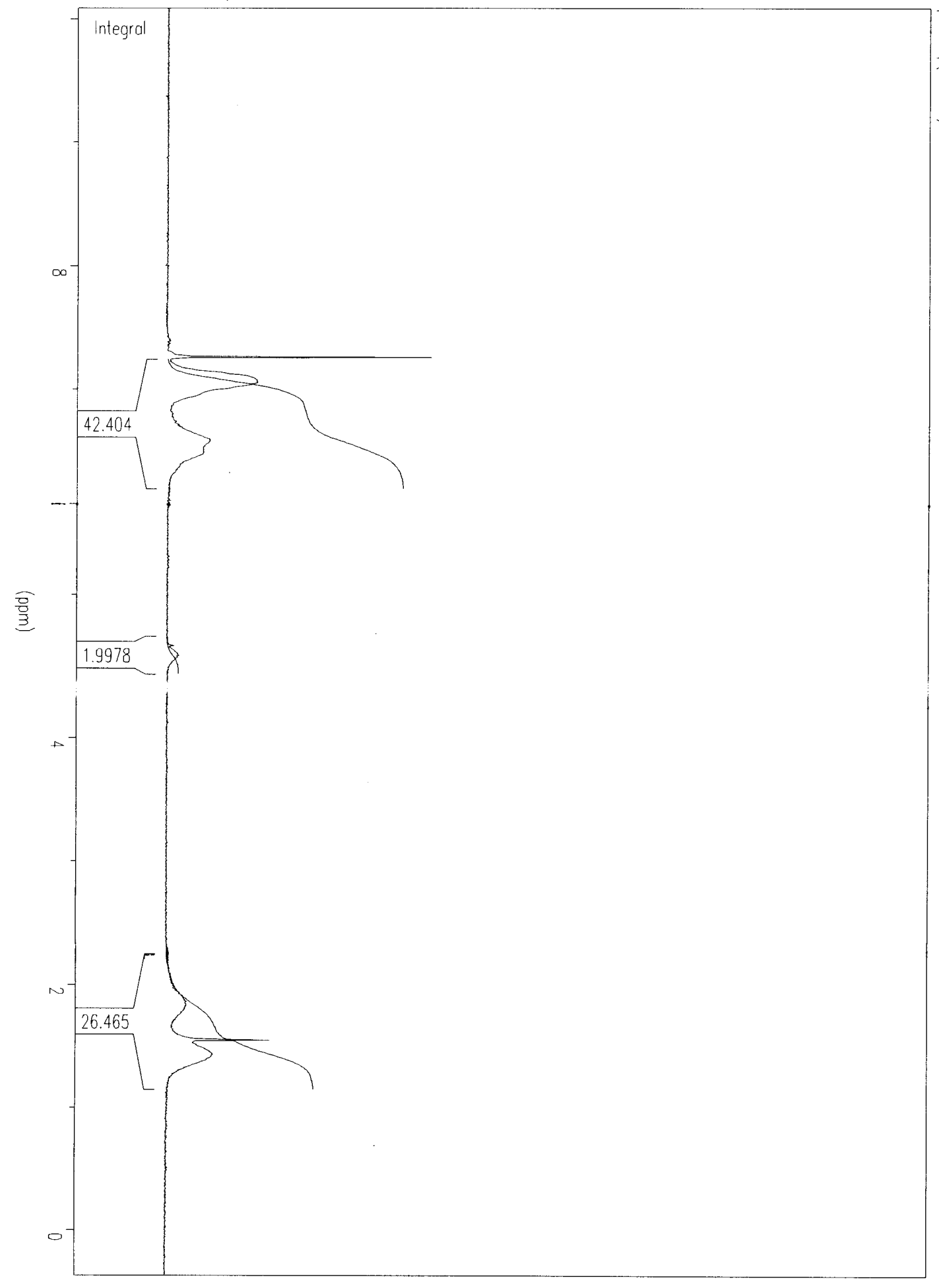


S17

\section{PS/S-Anth (28:13,40\%) - NMR}
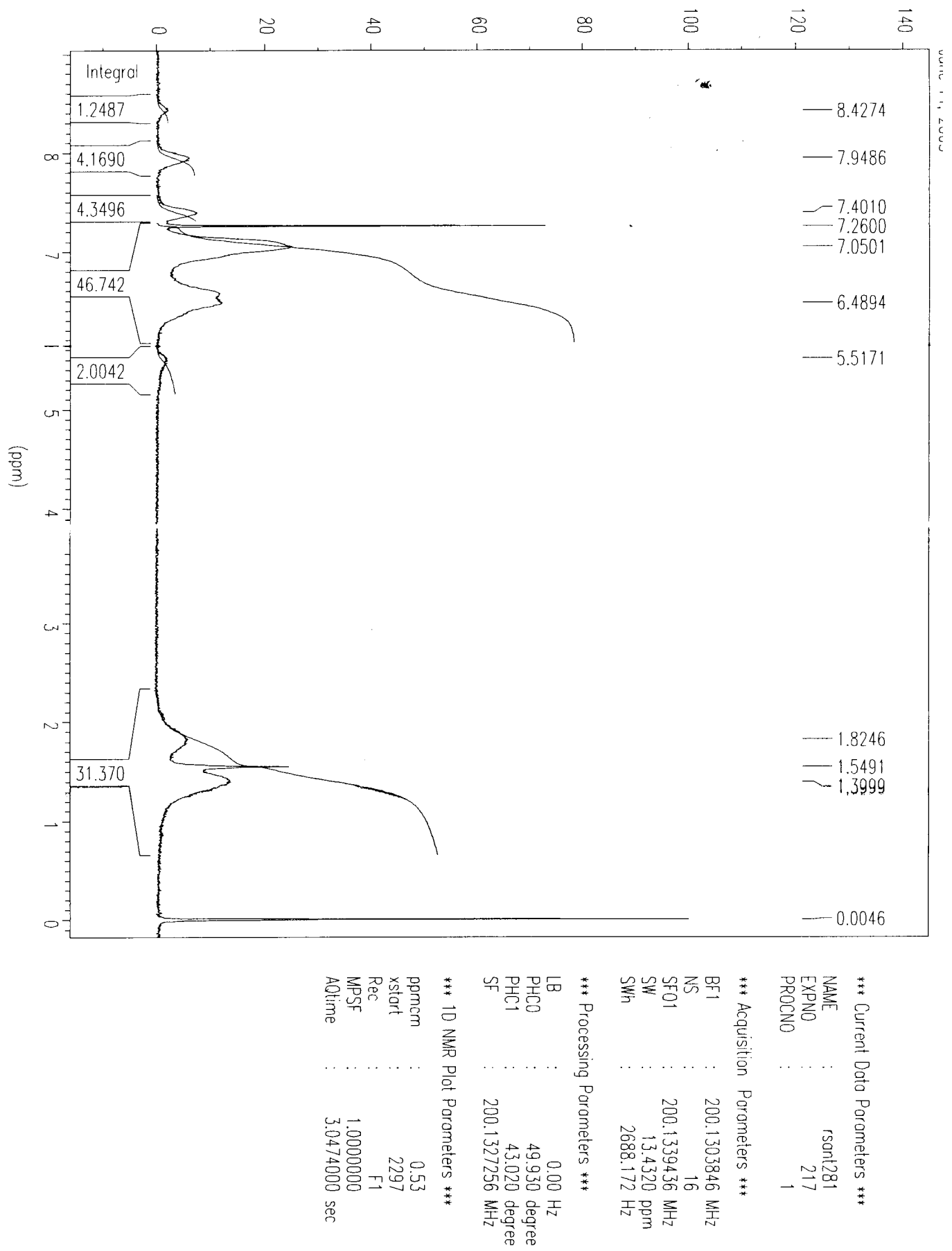
S18

PS/CMS (27:20,25\%) - GPC

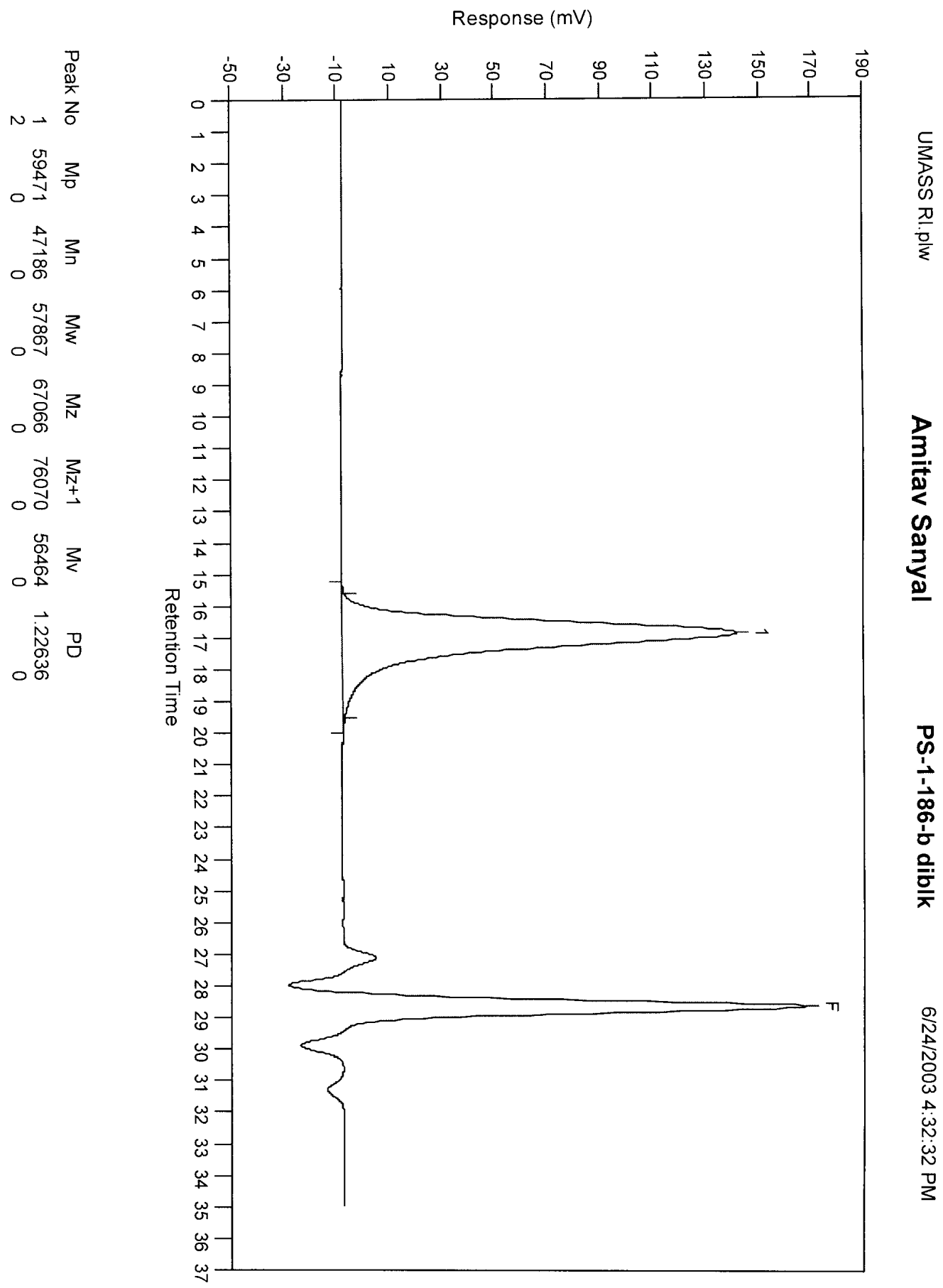


S19

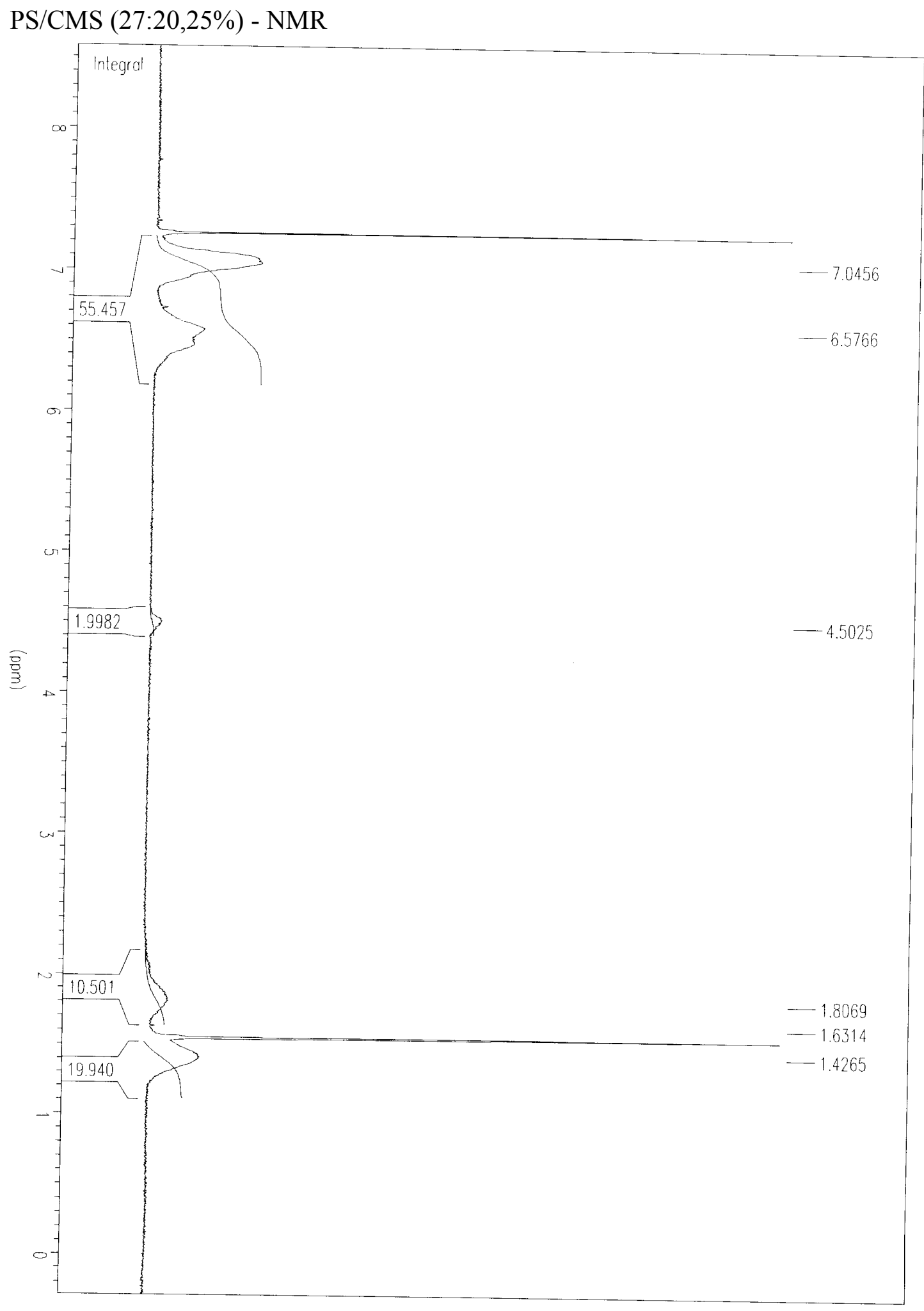


PS/S-Anth (27:20,25\%) - NMR

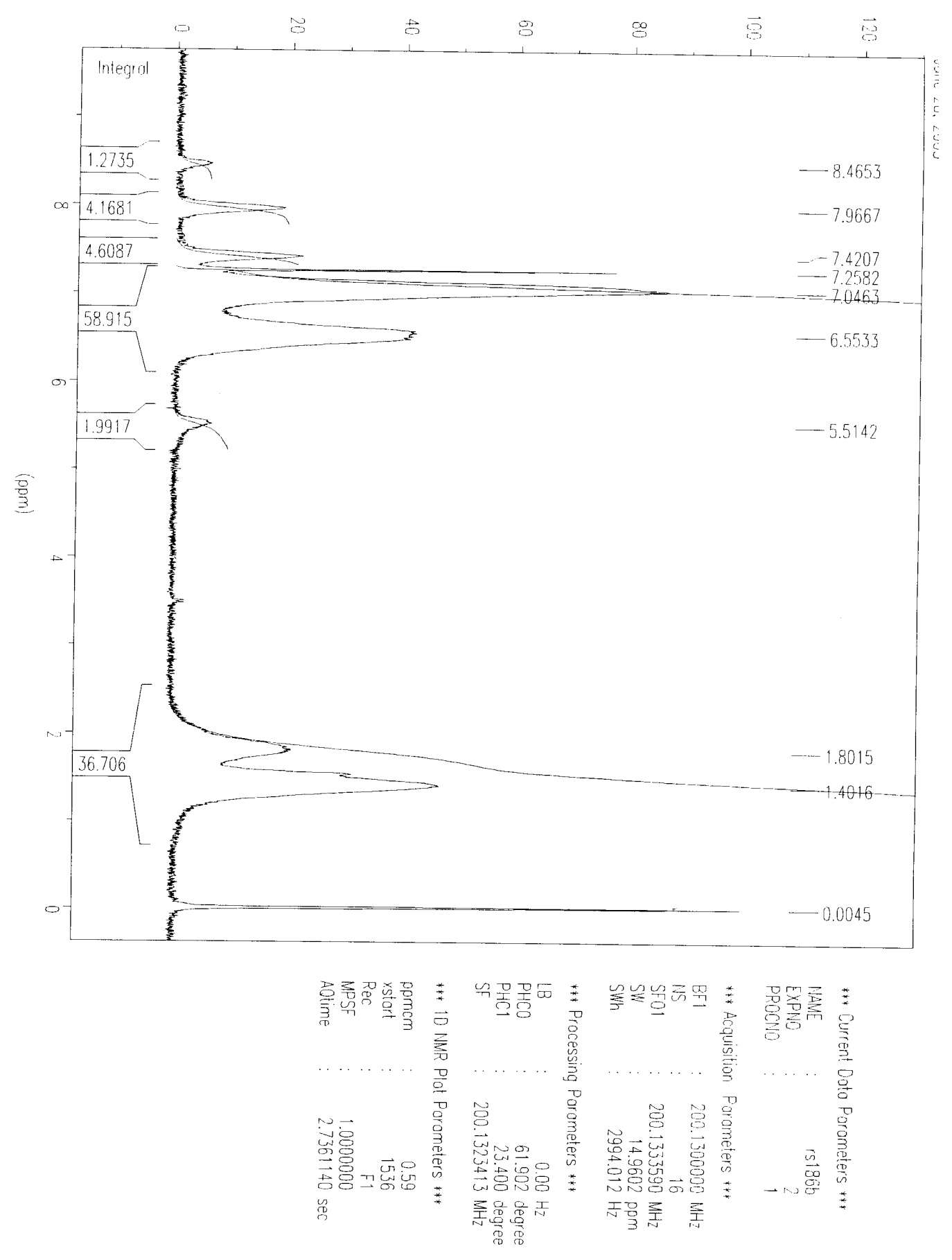


PS/CMS (27:23,20\%) - GPC

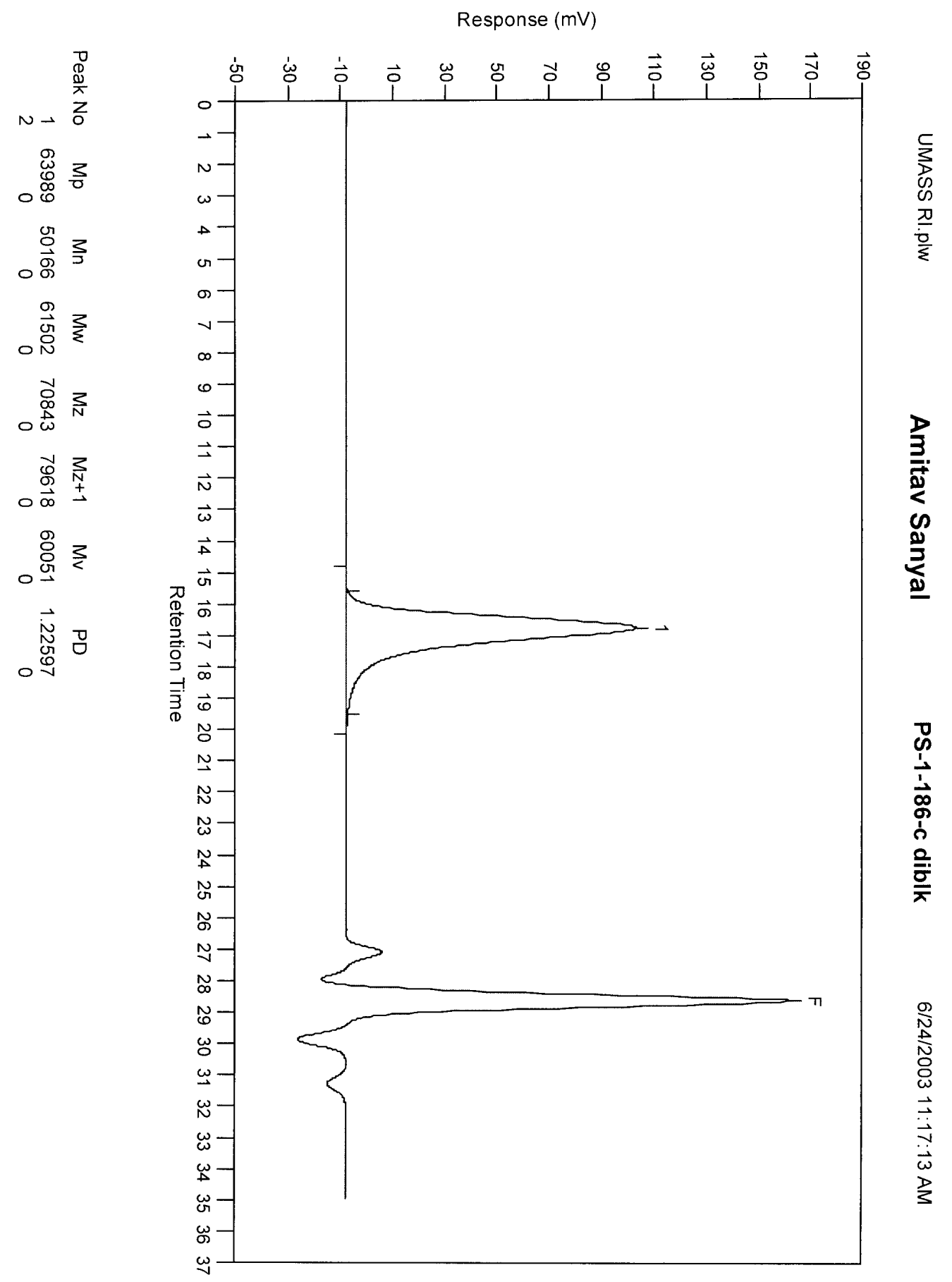




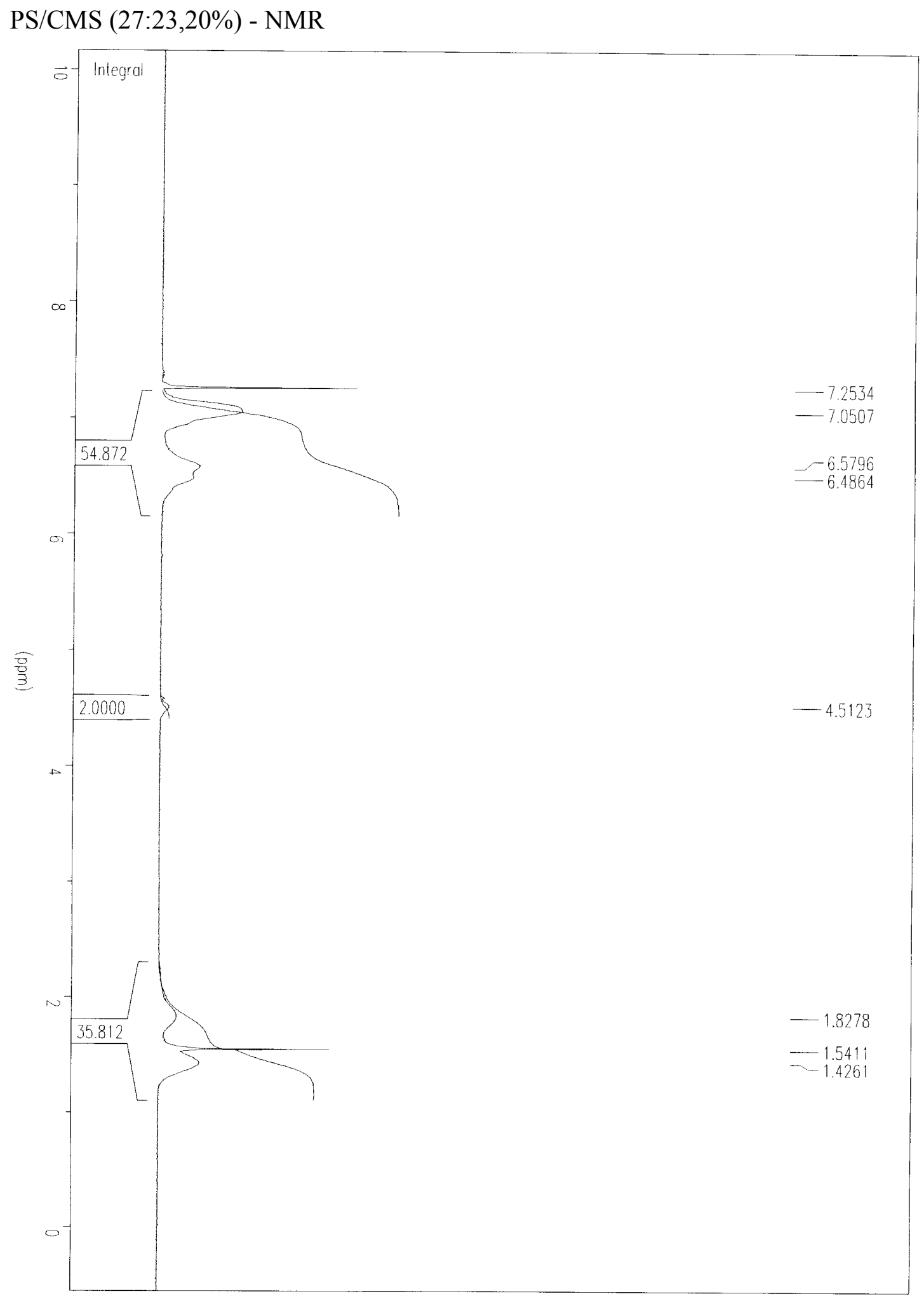


PS/S-Anth (27:23,20\%) - NMR

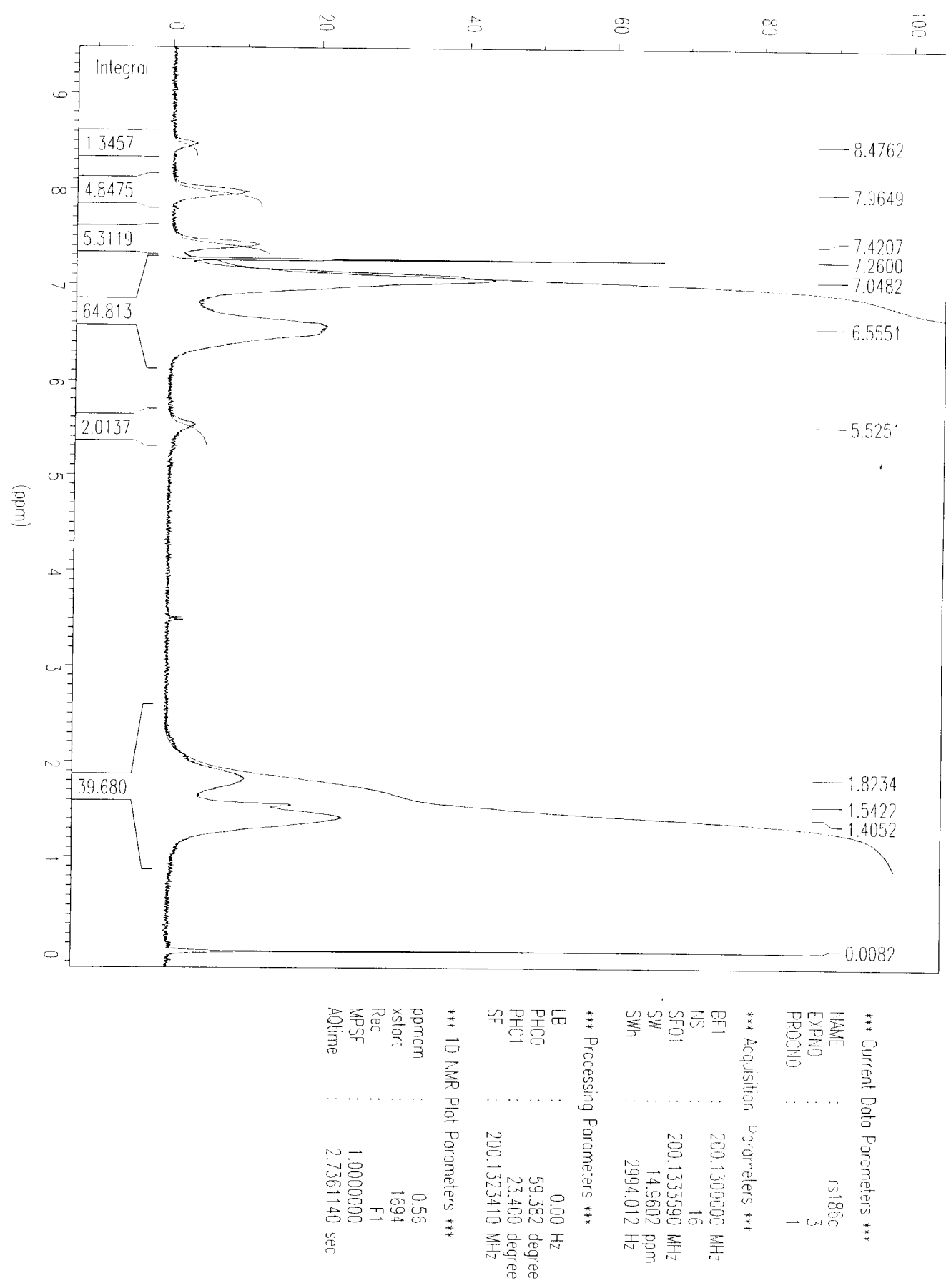


PS/CMS (27:26,22\%) - GPC

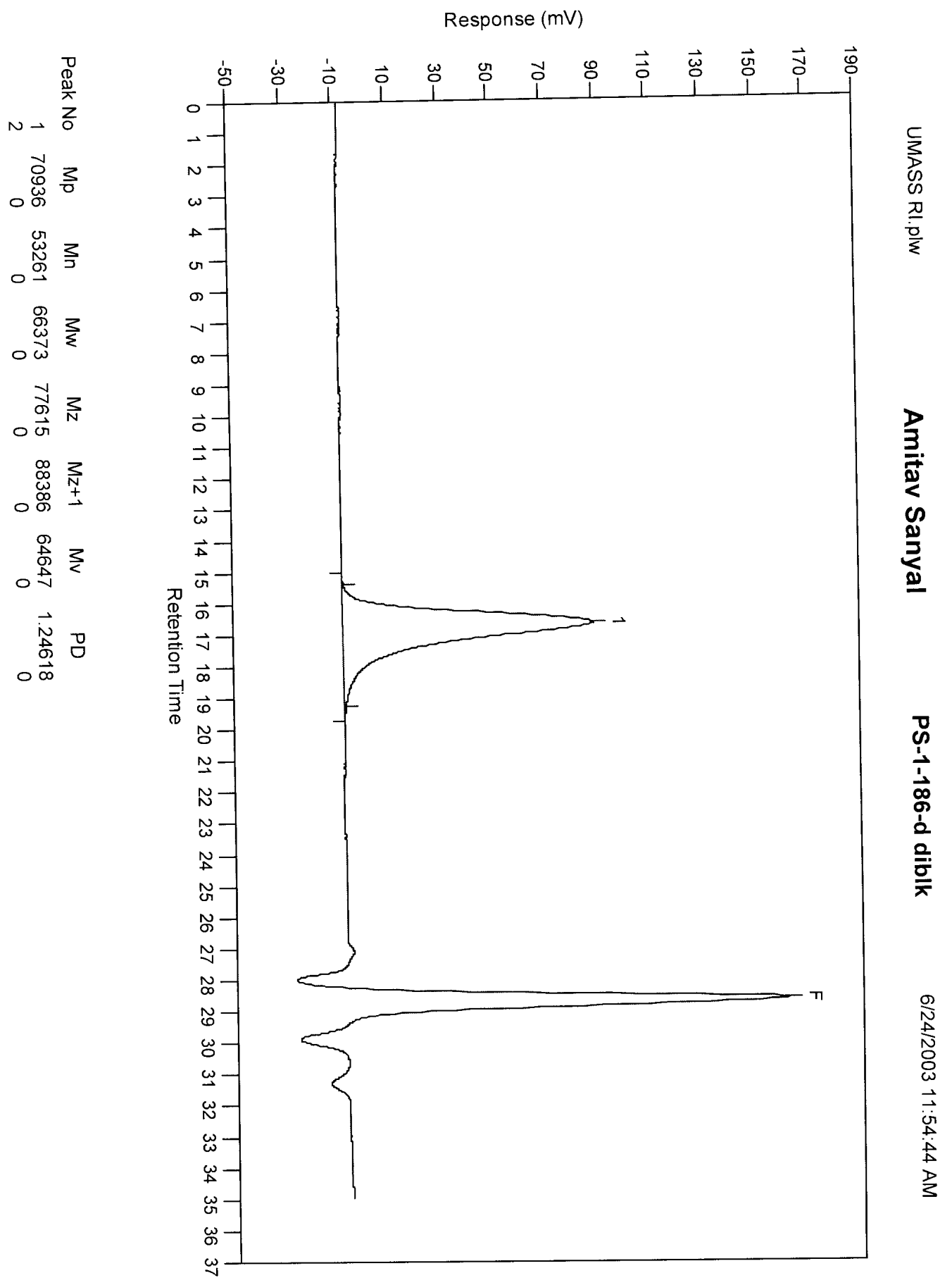


S25

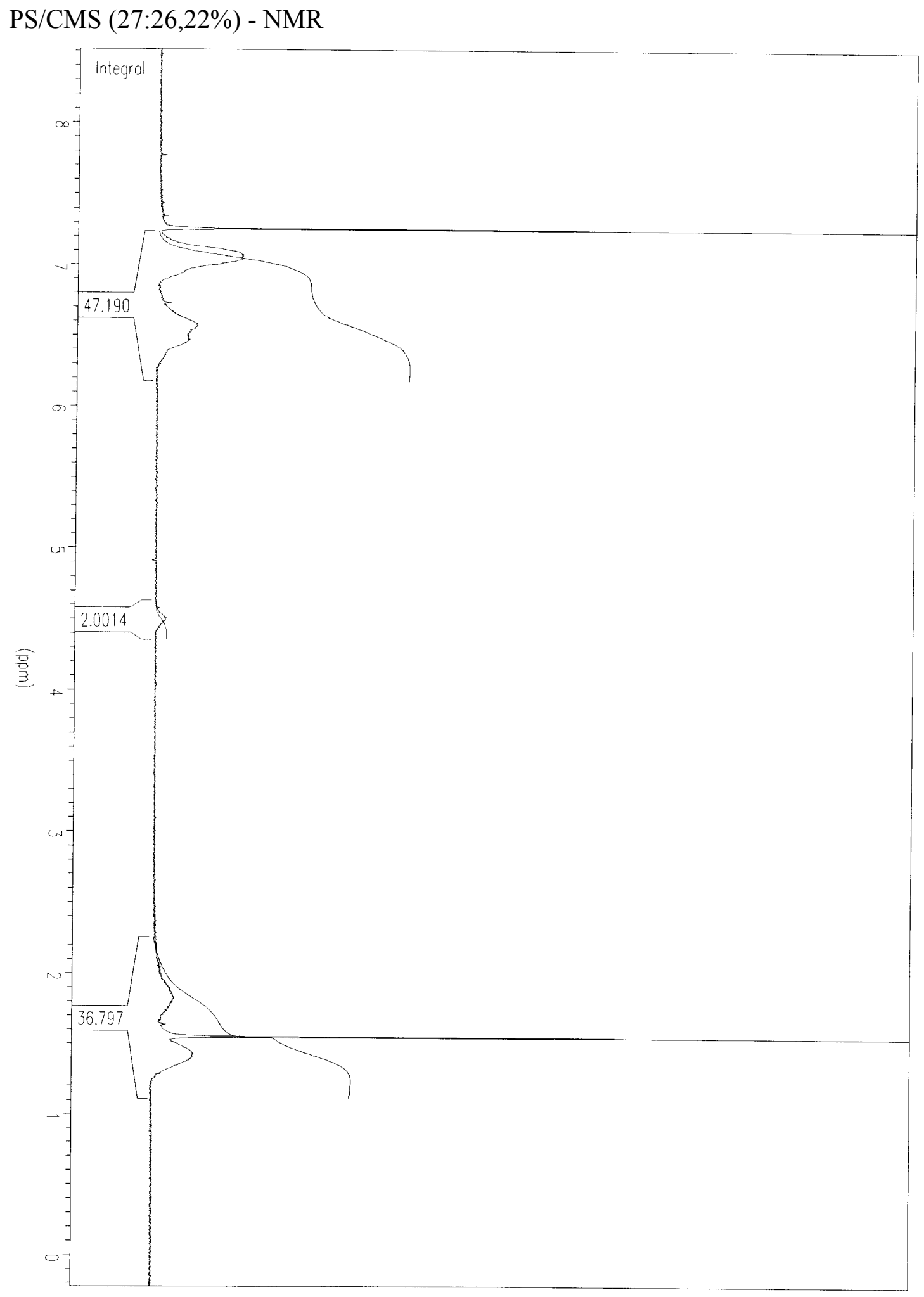


PS/S-Anth (27:26,22\%) - NMR

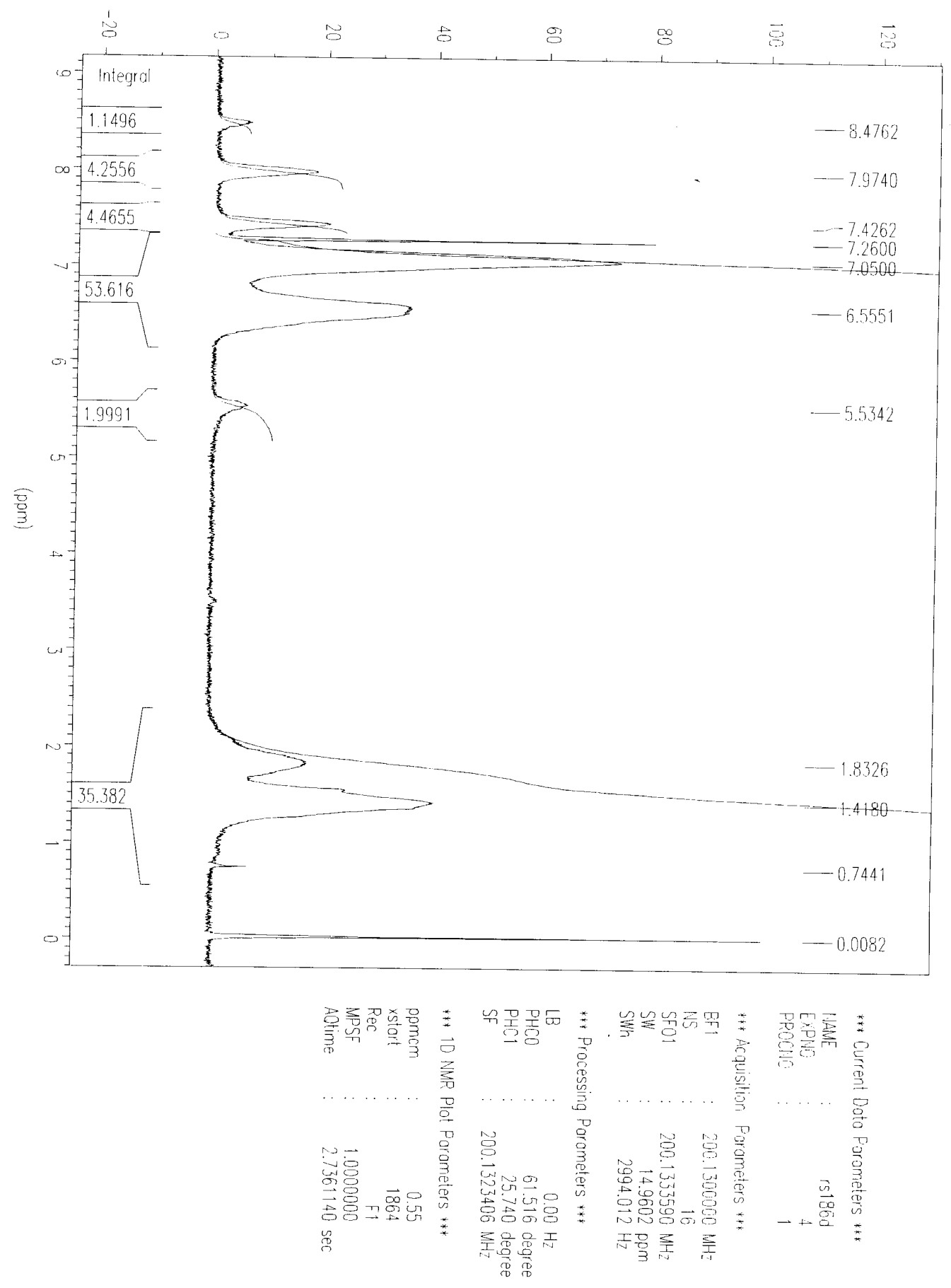

